\title{
Immediate extubation in cardiac surgery: evaluation using electroencephalogram
}

\author{
Extubação imediata em cirurgia cardíaca: avaliação pelo eletroencefalograma
}

Valdester Cavalcante PINTO JR. ${ }^{1,2}$, Rogean Rodrigues NUNES ${ }^{1,2,3}$, Claudia R. Carneiro SARDENBERG ${ }^{1}$, Klébia CASTELO BRANCO ${ }^{1}$, Maria Márcia SOUTO MAIOR ${ }^{1}$, Marcos Antônio Gadelha MAIA ${ }^{2}$, Patrícia Lopes SOUZA ${ }^{2}$, Fernando Antônio MESQUITA ${ }^{1,2}$, Haroldo Brasil BARROSO ${ }^{1,2}$, Juan Alberto Cosquillo MEJIA ${ }^{1,2}$, Jane Eyre Melo MOREIRA ${ }^{1,2}$, Ítalo Martins de OLIVEIRA ${ }^{4}$, Waldemiro CARVALHO JR. ${ }^{1,2}$.

\section{Abstract}

Background and objectives: The current techniques of anesthesia employed in cardiac surgery leading to immediate extubation depend on adequate analgesia and titration of anesthetic drugs. We sought to determine the best possible moment of extubation, using the bispectral index of the electroencephalogram.

Method: Twelve ASA III patients were analyzed. Seven $\mathbf{5 8 . 4 \% )}$ were children (Group I), submitted to correction of congenital cardiac defects with ages ranging from 0 to 7 years. Five adults (Group II), with ages ranging from 30 to 75 years, underwent coronary artery bypass grafts. In Group I spinal anesthesia (L5-S1) using hyperbaric $0.5 \%$ bupivacaine $(0.5 \mathrm{mg} /$ $\mathrm{kg})$ and morphine $(5 \mu \mathrm{g} / \mathrm{kg})$ was chosen. In Group II epidural anesthesia (T3-T4) with catheter placement plus ropivacaine $(60 \mathrm{mg})$ and morphine $(2 \mathrm{mg})$ were employed. For the induction of anesthesia fentanila $(4 \mu \mathrm{g} / \mathrm{kg})$, muscle relaxant and propofol (to bring the bispectral index value down to 30 ) were utilized. General anesthesia was maintained with sevofluorane, maintaining the bispectral index value between 40 and 60. Extubation was programmed at a bispectral index value of 90 .
Results: All patients were extubated up to one hour after the end of the surgical procedure, $91.6 \%$ of them in the operating room. All had the cognitive functions preserved without history of explicit memory or pain (adults and children who were able to speak), nor facial expression of pain (small children). Four (57\%) patients in Group I and one $(20 \%)$ in Group II had post-operative pruritus. Two patients $(28 \%)$ in Group II had emesis.

Conclusions: The results suggest that the technique employed is safe and effective, as long as the criteria for its use are strictly observed.

Descriptors: Electro-encephalography. Anesthesia. Cardiovascular surgical procedures.

Resumo:

Introdução: As técnicas empregadas em cirurgia cardíaca visando a extubação imediata (EI) dependem de analgesia adequada e titulação de drogas anestésicas.

Objetivo: A finalidade deste estudo é analisar a EI, utilizando eletroencefalograma (índice bispectral - BIS) para adequar o melhor momento de extubação.

Work completed in the Gastroclínica, São Mateus and São Lucas Hospitals. Fortaleza, Ceará, Brazil.

1 - Hospital Gastroclínica

2 - Hospital São Mateus

3 - Hospital São Lucas

4 - Medical School - UFC, Scholarship PIBIC/CNPq

Correspondence address:

Valdester Cavalcante Pinto Jr.

R. Gothardo Moraes, 155 apto 101-D

CEP: 60190-801. Fortaleza, Ceará - Brazil

Tel: (85) 272-8281. e-mail: valdester@terra.com.br 
Método: Foram analisados 12 pacientes, ASA III, 7 crianças (Grupo I) 58,4\%, com idades entre 0 e 7 anos, submetidas a correção cirúrgica de cardiopatias congênitas e 5 adultos (Grupo II), com idades entre 30 e 75 anos, submetidos a revascularização do miocárdio. No Grupo I realizou-se raquianestesia entre L5 e S1 com injeção de marcaína pesada $(0,5 \mathrm{mg} / \mathrm{kg})$ e morfina $(5 \mu \mathrm{g} / \mathrm{kg})$. No Grupo II realizou-se bloqueio epidural entre T3 e T4, com introdução de cateter e injeção de $60 \mathrm{mg}$ de ropivacaína e $2 \mathrm{mg}$ de morfina. Na indução da anestesia, empregamos: Fentanil $4 \mu \mathrm{g} / \mathrm{kg}$, propofol até BIS igual a 30 e relaxante muscular. A anestesia geral foi mantida com sevoflurano para BIS entre 40 e 60. Foi programada extubação quando o BIS atingisse 90.

\section{INTRODUCTION}

In heart surgery, the use of the electroencephalogram (ECG) (bispectral index and 95\% spectral margin frequency) is not commonly applied to adults, and no works utilizing ECG in pediatric heart surgery were found. The ECG allows us to maintain an adequate hypnotic state during surgical procedures with a better titration of anaesthetic drugs $[1,2]$. It also permits the evaluation of ischemic events with repercussions at the central nervous system level, indirect information of the quality of analgesia and a reduction in the incidence of explicit memories in heart surgery, principally when cardiopulmonary bypass (CPB) is used.

However, immediate extubation should be performed if the per- and post-operative analgesic scheme is effective. The advantages of analgesia include, apart from the possibility of early extubation using ECG, a reduction of the neuroendocrine response to trauma, improved ventilation conditions particularly in patients who suffered from previous pulmonary disease, as well as a reduced time in the intensive care unit. The aim of this study is to assess the possibility of immediate extubation (operation room) with monitoring of the effectiveness of analgesia by ECG processed after the use a per- and post-operative analgesia scheme.

\section{METHOD}

After approval from the ethics commission of the institution was attained, 12 patients with ASA III, were enrolled in the study. These patients included 5 adults with ages ranging from 30 to 75 years who underwent coronary artery bypass grafting with CPB and 7 children with ages varying from 0 to 7 years submitted to heart surgery for the correction of congenital defects - Table 1. The patients were divided into two groups: Group I -
Resultados: Todos os pacientes foram extubados até 1 hora após o término da operação, sendo $91,6 \%$ na sala de operações, com função cognitiva preservada, sem história de memória explícita, dor (adultos e crianças maiores) ou expressão facial de dor (crianças menores). Cinqüenta e sete por cento (4) dos pacientes do Grupo I e $20 \%$ (1) Grupo II apresentaram prurido e $28 \%$ (2) Grupo I apresentaram vômitos.

Conclusões: A técnica empregada mostrou-se segura e eficaz, desde que observados critérios rígidos para sua execução.

Descritores: Eletroencefalografia. Anestesia. Procedimentos cirúrgicos cardiovasculares.

children with analgesia achieved via a subarachnoid block and Group II - with analgesia achieved via an epidural block.

Table 1. Group I: Congenital heart disease

\begin{tabular}{lc}
\hline Surgical procedures & $\mathbf{N}^{\mathbf{0}}$ \\
\hline Ventriculoseptoplasty & 2 \\
Atriosseptoplasty & 2 \\
OAVC-T correction & 1 \\
canal arterial correction & 1 \\
Glenn's correction & 1 \\
\hline
\end{tabular}

$\mathrm{N}^{\mathrm{o}}=$ Number

In Group I, all the patients were pre-medicated with midazolam $(1 \mathrm{mg} / \mathrm{kg})$ via oral. Induction of anesthesia was performed with intravenous fentanyl $4 \mathrm{ig} / \mathrm{kg}$, propofol until a bispectral index (BIS) of 30 was attained and cisatracurio at $0.15 \mathrm{mg} / \mathrm{kg}$ intravenously (muscle relaxant). This was followed by subarachnoid anesthesia with an injection of marcaine at $0.5 \%$ body weight $(0.5 \mathrm{mg} / \mathrm{kg})$ associated with morphine sulfate $(5 \mathrm{ig} / \mathrm{kg}$ ) and later the patient was placed in the Trendelenburg position during 15 minutes.

In Group II, the patients were pre-medicated with intramuscular midazolam $(0.1 \mathrm{mg} / \mathrm{kg})$ and were submitted to epidural anesthesia between $\mathrm{T} 2$ and $\mathrm{T} 3$, with an injection of $1 \%$ ropivacain $(60 \mathrm{mg})$, associated with morphine sulfate (2 $\mathrm{mg}$ ). This was followed by general anesthesia with 
intravenous fentanyl at $4 \mathrm{ig} / \mathrm{kg}$, propofol until a BIS of 30 was reached and cisatracurio at $0.15 \mathrm{mg} / \mathrm{kg}$ intravenously.

General anesthesia, in both groups, was maintained using sevoflurane (before and after CPB) and propofol (during CPB) - Table 2, adjusted to maintain the BIS between 40 and 60 and the $95 \%$ spectral margin frequency (SEF) between 10 $\mathrm{Hz}$ and $14 \mathrm{~Hz}$, with ECG suppression events being recorded as a rate. Tachycardia and arterial hypertension events without increases in the BIS values were treated with betablockers and/or vasodilators (nitroglycerine). Elevations in the BIS without corresponding hemodynamic variations were treated by improving the hypnotic component of the anesthesia through the inhalation agent.

Table 2. Anesthetic drugs- technique protocol

\begin{tabular}{|c|c|c|}
\hline & Group I & Group II \\
\hline \multicolumn{3}{|l|}{ Pre-anesthesia } \\
\hline & Midazolam $1 \mathrm{mg} / \mathrm{kg}$ via oral & $\begin{array}{l}\text { Midazolam } 0.1 \mathrm{mg} / \mathrm{kg} \\
\text { intramuscular }\end{array}$ \\
\hline \multicolumn{3}{|l|}{ Block } \\
\hline & Subarachnoid & Epidural \\
\hline & Marcaine $0.5 \%$ heavy $(0.5 \mathrm{mg} / \mathrm{kg})$ & Ropivacaína 1\% (60 mg) \\
\hline & Morphine sulfate $5 \mu \mathrm{g} / \mathrm{kg}$ & Morphine sulfate $2 \mathrm{mg}$ \\
\hline & Trendelenburg 15 minutes & \\
\hline \multicolumn{3}{|l|}{ Induction } \\
\hline & Fentanyl $4 \mu \mathrm{g} / \mathrm{kg}$ intravenous & Fentanyl $4 \mu \mathrm{g} / \mathrm{kg}$ intravenous \\
\hline & Propofol to BIS 30 & Propofol to BIS 30 \\
\hline & Cisatracúrio $0.15 \mathrm{mg} / \mathrm{kg}$ & Cisatracúrio $0.15 \mathrm{mg} / \mathrm{kg}$ \\
\hline & intravenous & intravenous \\
\hline \multicolumn{3}{|l|}{ Maintenance } \\
\hline & Sevoflurane / Propofol* & Sevoflurane / Propofol* \\
\hline & BIS: $40-60$ & BIS: $40-60$ \\
\hline & $95 \%$ SEF: $10-14 \mathrm{~Hz}$ & $95 \%$ SEF: $10-14 \mathrm{~Hz}$ \\
\hline
\end{tabular}

* Utilized only during CEC.

In the operating room, the patients were monitored by means of: the mean invasive arterial pressure, heart beat, peripheral saturation of the hemoglobin, cardioscopy, nasopharygeal temperature, capnography, BIS and 95\% SEF utilizing a specific monitor (Aspect A-2000 - version 2.0 ${ }^{\circledR}$ ), with an adapted sensor for the following points (f8, Fz and Fp1) - Figure 1. BIS values of 40 and 60 and SEF values between $10 \mathrm{~Hz}$ and $14 \mathrm{~Hz}$ for the per-operative period and BIS greater or equal to 90 and $95 \%$ SEF greater than $20 \mathrm{~Hz}$ for tracheal extubation were considered adequate.

The time for tracheal extubation, considered as the time from the interruption of inhalation anesthesia (end of thoracotomy synthase) until obtaining satisfactory conditions for extubation, was recorded. These conditions were gasometric and electrolytic data within the satisfactory

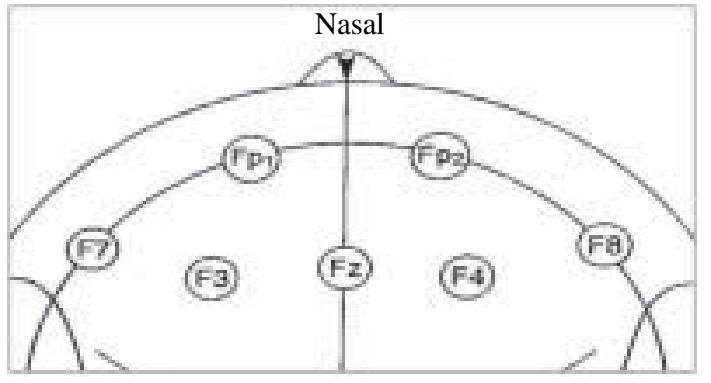

Fig. 1-International system of the placing of the electrodes. Nasal: point sited in the middle of the nasofrontal suture. $F p_{1}$ : Left frontal pole. $\mathrm{Fp}_{2}$ : Right frontal polo. $\mathrm{F} 7$ and $\mathrm{F3}$ : left frontal points. $\mathrm{F} 4$ and F8: right frontal points. Fz: frontal reference.

normal range, hemodynamic stability without the use or with minimum doses of vasoactive drugs, BIS $>90,95 \%$ SEF $>20$ $\mathrm{Hz}$, spontaneous respiration, absence of pain, normothermia and hemoglobin levels $>10 \mathrm{~g} / \mathrm{dL}$. The cognitive function was evaluated by the triple orientation test ${ }^{2}-$ (Group II), at minute intervals after tracheal extubation requesting the patient to respond to three questions: age, name and to name a part of the body.

Also the time of ICU stay and post-operative complications (vomiting, pruritus, urine retention, paresthesia, respiratory depression, infection at the puncture site of the anesthetic block and re-intubation) were recorded. Pain was evaluated by the facial pain expression scale in Group I and linear analogous scale (zero to ten) in Group II, where zero is no pain and ten intense pain. Exclusion criteria included: the presence of a pre-operative coagulopathy, central nervous system disease, thrombocytopenia, severe spinal deformity and systemic or local infection which did not permit epidural or spinal anesthesia blocks.

The statistical analysis employed was variance analysis according to the model of repeated measurements, with application of the Tukey test for the comparison of measurements between the two groups, in respect to the following items: 1) Time for tracheal extubation, 2) duration of CPB and 3) time of stay in the ICU. Where p-values $<0.05$ were considered significant.

\section{RESULTS}

The demographic data are demonstrated in Table 3. During the surgical procedures no suppression was seen on the ECG (Suppression rate $=0$ ). In group I, the mean tracheal extubation time was $19.8 \pm 1.4$ minutes and in Group II it was $23 \pm 8.2$ minutes (p-value < 0.05 ). Duration of CPB was $62.6 \pm 19.96$ and $85 \pm 19$ minutes in Groups I and II 
Table 3. Demographic Data

\begin{tabular}{lll}
\hline Variables & Group I & Group II \\
\hline Age (years)* & $2.45 \pm 3.6$ & $52.22 \pm 9.4$ \\
Weight (kg)* & $11.1 \pm 7.1$ & $70.20 \pm 7.4$ \\
Gender (Male / Female) & $4 \mathrm{M} / 3 \mathrm{~F}$ & $2 \mathrm{~F} / 3 \mathrm{M}$ \\
\hline
\end{tabular}

*mean \pm standard deviation

respectively (p-value $<0.05$ ). No positive scores of pain were evidenced in the immediate post-operative period when assessed based on the criteria previously described in this work.

Evaluation of the cognitive function based on the triple orientation test, utilized in Group II, was satisfactory in all the cases one minute after tracheal extubation. Urine retention, paresthesia, respiratory depression, infection (puncture), and re-intubation were not observed. The postoperative complications are listed in Table 4. The mean ICU stay time was $31.57 \pm 14.32$ hours for Group I and $33.6 \pm 10.0$ hours for Group II (p-value > 0.05).

Table 4. Post-operative complications

\begin{tabular}{lll}
\hline Complications & Group I & Group II \\
\hline Vomit & $28 \%(2)$ & 0 \\
Pruritus & $57 \%(4)$ & $20 \%(1)$ \\
\hline
\end{tabular}

\section{COMMENTS}

Since the middle of the 1980s, there has been a progressive change in the attitudes relating to the peroperative period of all operations from the smallest to the greatest $[3,4]$. This change is related to an adoption of institutional policies, primarily aiming at a reduction in the costs of procedures and maximizing the utilization of operation rooms and the beds in the intensive care and on the hospital ward. With these priorities in mind, institutional multidisciplinary committees were created with the task of planning and organizing the procedures in such a way as to achieve the aforementioned objectives, through what became known as fast-track protocols. Such committees also supervised the execution and control of rendered services $[5,6]$.

In larger surgeries, especially those traditionally associated with prolonged post-operative mechanical ventilation, the greatest goal has been to reduce the postoperative mechanical ventilation time, thus minimizing its adverse effects and reducing the time spent in the ICU. These adverse effects can be infectious or non-infectious (polyneuropathy, volutrauma, barotrauma, atelectatic trauma, biotrauma, bronco-trauma and toxicity caused by oxygen). Some studies have demonstrated that these two factors are responsible for a substantial reduction of hospital costs and contribute, in the absence of post-operative complications, to reduce the time of hospital stay of patients submitted to major surgeries [7-10].

Anesthesiologists have a fundamental role to play in the success of fast-track protocols, as they are responsible for early extubation and for the treatment of post-operative pain.

Early extubation occurs in the first six post-operative hours and immediate extubation is defined as occurring inside the operation room. Extubation that occurs after eight to ten hours in the post-operative period is considered late.

Immediate and early extubation have been successfully performed in several types of major surgeries, such as thoracic [11,12] abdominal aorta [13], oesophagectomy [14,15], major orthopedic surgeries [16] and liver transplantation [17]. The benefits for the patients of fasttrack recoveries include a lower rate of respiratory complications and hyperhydratation. These advantages have been converted in reduced stays in the ICU, as well as earlier mobility, feeding and hospital release. Additionally, these advantages are due to the implantation of clinical protocols which include the association of different types of anesthesia, the use of hemodilution, antifibrinolytic agents, prevention of hypothermia and hyperhydratation, a better gasometric control and other pharmacological and physiotherapeutic measures with the aim of accelerating post-operative recovery.

In no field has fast-track recovery been more adept than in cardiac surgery, for CABG and valve and congenital procedures. However, it is important to stress that to use this technique, we need to employ two important procedures: 1. An efficient scheme of per- and postoperative analgesia, which in this work were epidural and subarachnoid blocks, which act to reduce the stress and reduce the morbid-mortality associated with cardiac surgery [18-21] and 2. Electroencephalographic monitoring of the depth of anesthesia, focusing on three control variables a). the BIS, b). the $95 \%$ SEF and c). an estimate of the burst suppression ratio.

Electroencephalographic monitoring of the depth of anesthesia is an old concept based on the depressor effects of inhalation anesthetics on the central nervous system. When the dose of the inhalation anesthetics increases, there is a progressive loss of consciousness and somatic 
suppressions and the autonomic responses and harmful stimuli. EEG has been studied very much and a number of signals that were processed was developed to facilitate its interpretation [22]. An extensive database of highly reliable EEG readings has been formed over the years, originating from patients submitted to one of the following anesthetic regimens: isoflurane/02, propofol/N20, propofol/alfentanil/ N20, propofol/regional and midazolam/regional.

EEG measurements of sedation were developed based on the observation that the EEG of the patient generally changes from a high frequency signal with low amplitude, when wide awake, to a low frequency signal with great amplitude when profoundly anesthetized. In very high doses, all the activity can disappear, leading to an isoelectric EEG (suppressed) - Fig. 2.

\author{
$\operatorname{BETA}(13-30 \mathrm{~Hz})$ \\ (Awake and alert) \\ $\operatorname{ALFA}(8-13 \mathrm{~Hz})$ \\ (closed eyes, relaxed) \\ $\operatorname{TETA}(4-7 \mathrm{~Hz})$ \\ $\operatorname{DELTA}(0-4 \mathrm{~Hz})$ \\ (deep sleep, deep sedation) \\ Suppression event \\ (Very deep sedation, hypothermia and ischemia)
}

Fig. 2 - Types of EEG waves according to the frequency band.

As in all signals, EEG can be split down to a series of components of sinusoid waves in a way that when the components are rejoined, the original signal is recovered. The break down of an EEG signal is typically made with the intention of characterizing the signal by a unique number or set of numbers which enables observations of a tendency over time. These numbers are called "processed parameters". The majority of EEG processed parameters used today, are based on a technique called "potential spectrum analysis", which represents the amplitude or potency of each one of the components of the sinusoid waves as a function of the frequency. A very common parameter, destined to accompany the alterations that occur with the deepening of hypnosis, is called the "95\% spectral margin frequency". This consists

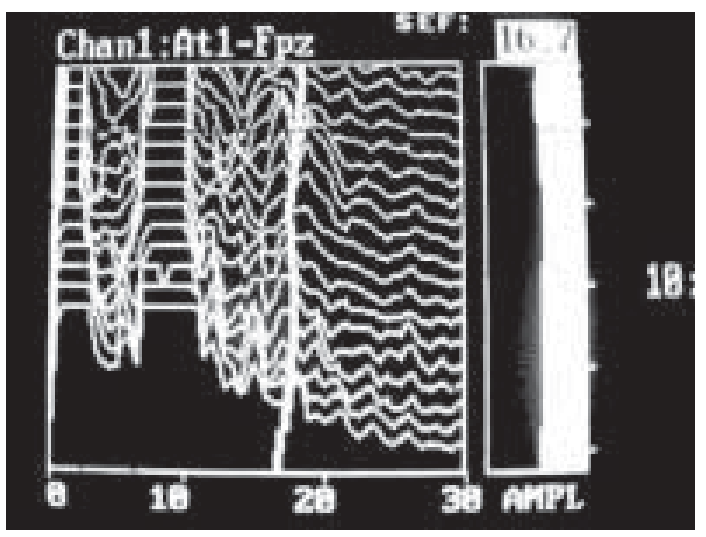

Fig. $3 A-95 \%$ SEF (CSA).

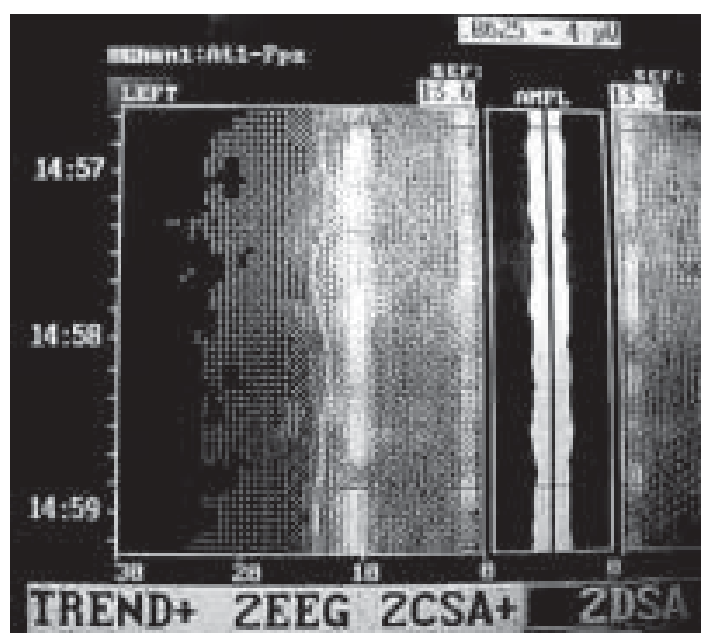

Fig. $3 B-95 \%$ SEF (DSA).

of a low frequency, the potency spectrum of which contains $95 \%$ of the total potency of the EEG (Figures $3 \mathrm{~A}$ and $3 \mathrm{~B}$ ).

The bispectral analysis is a method that examines the relationship between the components of the wave or its formation in pairs. As it is related to the potency spectrum analysis, it extracts extra data about the signal generation process. Aspect medical Systems ${ }^{\circledR}$ reduced, by means of a sophisticated algorithm, the complex sets of data generated by spectral analysis, creating a compound and numerical, bispectral Index [23], capable of accompanying alterations of the cerebral state (Figure 4 and Table 5).

This study shows that, observing established parameters, the program for immediate extubation after heart surgery is safe as long as certain conditions are followed. These include electroencephalographic monitoring and that the general anaesthetic is associated with a conductive block 
(subdural or epidural), with lower risks associated to mechanical ventilation (both hemodynamics and pulmonary) $[24,25]$, apart from a reduction in the ICU stay (observed in Groups I and II). This can imply a reduction in costs in this unit, which was demonstrated by Cheng et al. [26]. Hammer et al. [18], in a recent study, obtained an average UTI stay, for the pediatric population submitted to heart surgery of $43.2 \pm 3.6$ hours. These data differ from the results obtained in this work in relation to group I (children), which presented a mean UTI stay of only $31.57 \pm 14.32$ hours. However, the authors did not utilize electroencephalographic monitoring,

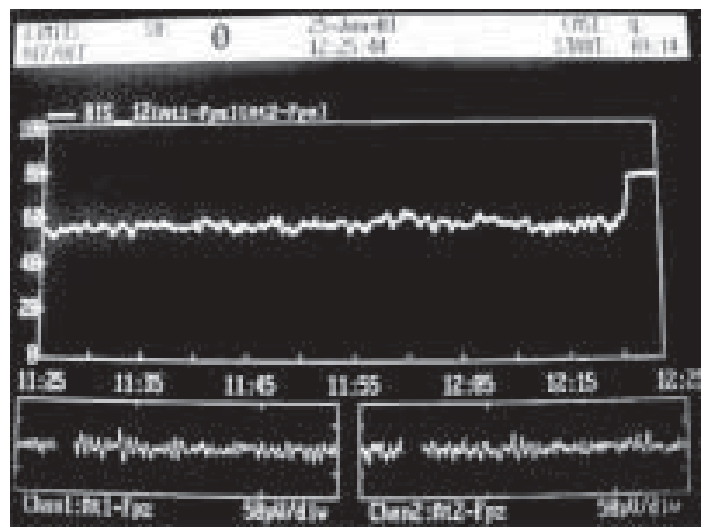

Fig. 4 - BIS (Bispectral Index).

Table 6. Relation between the clinical state of the patients and BIS, altered for the use of hypnotic sedatives.

\begin{tabular}{cll}
\hline BIS Level & \multicolumn{1}{c}{ Clinical Condition } & \multicolumn{1}{c}{ EEG } \\
\hline 100 & Awake & \\
$80-70$ & Sedated & High frequency activity \\
60 & moderate hypnotic state & Low frequency activity \\
40 & deep hypnotic state & suppression of parts of EEG \\
0 & isoelectric EEG & Total suppression \\
\hline
\end{tabular}

which may be an important factor, which differentiates the two investigations.

Statistical analysis of the tracheal extubation times, despite showing a significant difference between the two groups $(\mathrm{GI}=19.8 \pm 1.4$ minutes and $\mathrm{GII}=23.0 \pm 8.2$ minutes - p-value $<0.05)$, is clinically irrelevant. Thus, we conclude that the method is safe and efficient, as long as rigid criteria for its use are observed.

\section{BIBLIOGRAPHIC REFERENCES}

1. Nunes RR, Cavalcante SL, Serpa AKL, Bezerra GA. Redução do consumo de sevoflurano com monitorização pelo BIS. Rev Bras Anestesiol 2001; 51(supl.27):007A.

2. Nunes RR, Cavalcante SL, Ibiapina RCP, Lopes KCM. Análise bispectral do tempo de despertar e avaliação da recuperação da psicomotricidade e da consciência em anestesias com desflurano ou sevoflurano. Rev Bras Anestesiol 2000;50:202-6.

3. Chong JL, Pillai R, Fisher A, Grebenik C, Sinclair M, Westaby S. Cardiac surgery: moving away from intensive care. Br Heart J 1992; 68:430-3.

4. Westaby S, Pillai R, Parry A, O'Regan D, Giannopoulos N, Grebenik K et al. Does modern cardiac surgery require conventional intensive care? Eur J Cardiothorac Surg 1993; 7:313-8

5. Michalopoulos A, Nikolaides A, Antzaka C, Deliyanni M, Smirli A, Geroulanos S et al. Change in anaesthesia practice and postoperative sedation shortens ICU and hospital length of stay following coronary artery bypass surgery. Respir Med 1998; 92: 1066-70.

6. Silbert BS, Santamaria JD, O'Brien JL, Blyth CM, Kelly WJ, Molnar RR. Early extubation following coronary artery bypass surgery: a prospective randomized controlled trial. The Fast Track Cardiac Care Team. Chest 1998; 113:1481-8.

7. Cheng DC. Pro: early extubation after cardiac surgery decreases intensive care unit stay and cost. J Cardiothorac Vasc Anesth 1995; 9:460-4.

8. Cheng DC. Impact of early tracheal extubation on hospital discharge. J Cardiothorac Vasc Anesth 1998; 12 (6 Suppl 2):35-44.

9. Cheng DC. Fast-track cardiac surgery: economic implications in postoperative care. J Cardiothorac Vasc Anesth 1998; 12:72-9.

10. Cheng DC. Fast- track cardiac surgery pathways: early extubation, process of care and cost containment. Anesthesiology 1998; 88: 1429-33.

11. Zehr KJ, Dawson PB, Yang SC, Heitmiller RF. Standardized clinical care pathways for major thoracic cases reduce hospital costs.AnnThorac Surg 1998; 66:914-9.

12. Desiderio D, Downey R. Critical issues in early extubation and hospital discharge in thoracic oncology surgery. J Cardiothorac Vasc Anesth 1998; 6 (Suppl 2):3-6, discussion 41-4.

13. Mason RA, Newton GB, CasseI W, Maneksha F, Giron F. Combined epidural and general anesthesia in aortic surgery. J Cardiovasc Surg 1990; 31: 442-7. 
14. Brodner G, Pogatzki E, Van Aken H, Buerkle H, Goeters C, Schulzki C et al. A multimodal approach to control postoperative pathophysiology and rehabilitation in patients undergoing abdominothoracic esophagectomy. Anesth Analg 1998; 86:228-34.

15. Kahn L, Baxter FJ, Dauphin A, Goldsmith C, Jackson PA, McChesney $\mathrm{J}$ et al. A comparison of thoracic and lumbar epidural techniques for post- thoracoabdominal esophagectomy analgesia. Can J Anaesth 1999; 46:415-22.

16. Rosenberg AD. Ensuring early discharge following major surgery: orthopedic surgery. J Cardiothorac Vasc Anesth 1998; 12(6 Suppl 2):7-10, discussion 41-4.

17. Mandell MS, Lockrem J, Kelley SD. Immediate tracheal extubation after liver transplantation: experience of two transplant centers. Anesth Analg 1997; 84:249-53.

18. Hammer GB, Ngo K, Macario A. A retrospective examination of regional plus general anesthesia in children undergoing open heart surgery. Anesth Analg 2000; 90:1020-4.

19. Stenseth R, Bjella L, Berg EM, Christensen O, Levang OW, Gisvold SE. Thoracic epidural analgesia in aortocoronary bypass surgery. II: Effects on the endocrine metabolic response. Acta Anaesthesiol Scand 1994; 38:834-9.

20. Moore CM, Cross MH, Desborough JP, Burrin JM, Macdonald IA, Hall GM. Hormonal effects of thoracic extradural analgesia for cardiac surgery. Br J Anaesth 1995; 75:387-93.
21. Fawcett WJ, Edwards RE, Quinn AC, MacDonald IA, Hall GM. Thoracic epidural analgesia started after cardiopulmonary bypass: adrenergic, cardiovascular and respiratory sequelae. Anaesthesia 1997;52:294-9.

22. Chan MT, Gin T. What does the bispectral EEG index monitor? Eur J Anaesthesiol 2000;17:146-8.

23. Rampil IJ. A primer for EEG signal processing in anesthesia. Anesthesiology 1998;89:980-1002.

24. Romaldini H. Repercussões cardiovasculares da ventilação mecânica. In: Auler Jr. JOC, Amaral RVG, editores. Assistência ventilatória mecânica. 1a. ed. São Paulo: Atheneu; 1995. p.115-20.

25. Auler Jr. JOC, Pereira JCD. Efeitos pulmonares da ventilação mecânica. In: Auler Jr. JOC, Amaral RVG, editores. Assistência ventilatória mecânica. 1a. ed. São Paulo: Atheneu; 1995. p.121-8.

26. Cheng DC, Karski J, Peniston C, Raveendran G, Asokumar B, Carroll J et al. - Early tracheal extubation after coronary artery bypass graft surgery reduces costs and improves resource use: a prospective, randomized, controlled trial. Anesthesiology 1996; 85:1300-10. 